\title{
In vitro Characterization of the Oxidation of a Pyridinium Metabolite of Haloperidol by Human Placenta: The Effect of Smoking
}

\author{
Jim Fang ${ }^{1, *}$ and Jiuxue Song ${ }^{1}$ \\ ${ }^{1}$ College of Pharmacy and Nutrition, University of Saskatchewan, Saskatoon, SK, Canada. \\ Received, March 5, 2012; Revised, August 14, 2012; Accepted, September 10, 2012; Published, September $29,2012$.
}

\begin{abstract}
Purpose. The antipsychotic drug haloperidol can be metabolised to pyridinium metabolites haloperidol pyridinium $\left(\mathrm{HP}^{+}\right)$and reduced haloperidol pyridinium $\left(\mathrm{RHP}^{+}\right)$. These pyridinium metabolites were proposed to contribute to the extrapyramidal side effects of haloperidol, because they are structural analogues of $\mathrm{N}$-methyl-4-phenylpyridinium $\left(\mathrm{MPP}^{+}\right.$), a well-known neurotoxin. $\mathrm{RHP}^{+}$can be oxidized to $\mathrm{HP}^{+}$by CYP1A1. In the current study, the oxidation of $\mathrm{RHP}^{+}$to $\mathrm{HP}^{+}$was investigated using human placenta microsomal preparations which contain relatively high levels of CYP1A1. Methods. Cytochrome P450 isoenzymes responsible for the metabolism of $\mathrm{RHP}^{+}$were characterized in vitro using human placenta microsomal preparations from smokers and non-smokers. Results. A comparison of the metabolic activities between smokers and non-smokers suggests that smokers had higher activities for the oxidation of $\mathrm{RHP}^{+}$. A selective antibody against CYP1A1 was a partial inhibitor of $\mathrm{RHP}^{+}$oxidase in placenta from smokers but had no effect in placenta from non-smokers. Furafylline and ketokonazole were shown to be stronger inhibitors of the oxidation of $\mathrm{RHP}^{+}$to $\mathrm{HP}^{+}$in liver than in placenta. This seems to indicate important contributions of CYP1A1 and CYP3A7 as compared to CYP1A2 and CYP3A4, respectively, because furafylline and ketokonazole are stronger inhibitors of CYP1A2 and CYP3A4 than CYP1A1 and CYP3A7, respectively. Interestingly, $\alpha$-naphathoflavone enhanced the metabolic activity in liver microsomes due to its activator effect on CYP3A4. On the other hand, $\alpha$-naphathoflavone partially inhibited the activity in placenta microsomes, indicating a role played by CYP1A1 or CYP1A2 in the oxidation of RHP ${ }^{+}$in placenta. Conclusions. These data indicate that CYP1A1 plays an important role in the oxidation of $\mathrm{RHP}^{+}$to $\mathrm{HP}^{+}$in placenta from smokers. CYP3A7 and CYP3A4 could also play important roles in the metabolism of $\mathrm{RHP}^{+}$in placenta microsomes.
\end{abstract}

This article is open to POST-PUBLICATION REVIEW. Registered readers (see "For Readers") may comment by clicking on ABSTRACT on the issue's contents page.

\section{INTRODUCTION}

The antipsychotic drug haloperidol [4-[4-(4chlorophenyl)-4-hydroxy-1-piperidinyl]-1-(4'fluorophenyl)-1-butanone] can induce movement disorders in patients which is a major concern in its clinical use. Haloperidol was shown to be converted to a pyridinium metabolite, 4-(4-chlorophenyl)- 1(4-fluorophenyl)-4-oxobutylpyridinium $\left(\mathrm{HP}^{+}\right)$(1-4). Further studies identified reduced $\mathrm{HP}^{+}\left(\mathrm{RHP}^{+}\right)$[4(4-chlorophenyl)- 1-(4-fluorophenyl)-4hydroxybutylpyridinium] in the plasma and urine of haloperidol treated patients (5). Both $\mathrm{HP}^{+}$and $\mathrm{RHP}^{+}$ are structurally similar to N-methyl-4phenylpyridium $\left(\mathrm{MPP}^{+}\right)$, a well-known neurotoxin that causes Parkinson's syndrome in human and experimental animals. As haloperidol induces pronounced and sometimes irreversible movement disorders in its clinical use, it was proposed that the pyridinium metabolites may contribute to these side effects.

$\mathrm{HP}^{+}$and $\mathrm{RHP}^{+}$has been detected in the brains of patients who have chronically received haloperidol (6). Average brain concentrations of $\mathrm{HP}^{+}$and $\mathrm{RHP}^{+}$were found to be 4.1 and $2.7 \mathrm{pmol} / \mathrm{g}$ tissue 14-25 hours post-mortem. It was suggested that $\mathrm{HP}^{+}$is formed mainly in the liver and can pass through the blood-brain barrier (7). Both $\mathrm{HP}^{+}$and $\mathrm{RHP}^{+}$were found to be substrates of organic cation transporters present in the brain suggesting a possible role of active transporters in their passage through the blood-brain barrier (8).

Corresponding Author: Jim Fang, College of Pharmacy and Nutrition, University of Saskatchewan, Saskatoon, Saskatchewan, Canada; E-mail: jim.fang@usask.ca 
Numerous studies have been conducted to examine the neurotoxicity of the pyridinium metabolites of haloperidol in the brain. Baboons developed orofacial dyskinesia following chronical treatment with the dehydration product of haloperidol (HTP, 4-(4-chlorophenyl)-1-[4-(4-fluorophenyl)-4-

oxobutyl]-1,2,3,6-tetrahydropyridine) which is metabolized to $\mathrm{HP}^{+}$and $\mathrm{RHP}^{+}(9)$. The induced orofacial dyskinesia persisted after HTP was ceased and is accompanied by loss of neurons. Intrastriatal microdialysis studies in rat brain showed that perfusion of $\mathrm{HP}^{+}$leads to irreversible depletion of striatal dopamine, although $\mathrm{HP}^{+}$was less potent than $\mathrm{MPP}^{+}$(10). However, intracortical microdialysis studies indicated that the two compounds displayed comparable toxic effects on the cortical serotonergic system (10). In vitro studies shown that $\mathrm{HP}^{+}$was a more potent inhibitor of mitochondrial respiration than $\mathrm{MPP}^{+}(10) . \mathrm{HP}^{+}$ was also found to be toxic to dopaminergic and serotonergic neurons in cultures of embryonic mesencephalic cells and human neuroblastoma SHSY5Y cells $(11,12)$. Additionally, $\mathrm{HP}^{+}$was found to be a potent inhibitor of dopamine and noradrenaline uptake (13) and a inhibitor of monoamine oxidase (14). The strongest support so far for the "pyridinium hypothesis" of the extrapyrimidal side effects of haloperidol cames from a study on 41 psychiatric patients on longterm treatment with haloperidol. It was found that the severity of tardive dyskinesia and parkinsonism is strongly associated with an increased ratio of $\mathrm{HP}^{+} /$haloperidol in serum (15). Although other types of antipsychotic drugs such as chlorpromazine also produce movement disorders, severe tardive dyskinesia is found most often for haloperidol and bromperidol $(15,16)$.

The metabolism of haloperidol has been characterized in vitro using human liver microsomes and recombinant human cytochrome P450 isoenzymes $(17,18)$. In the experiments with a panel of human liver microsomes from 12 donors, the metabolic activities on haloperidol were correlated with catalytic activities of selective substrates of different P450 isoenzymes and immuno-reactivities toward different P450 isoenzymes. It was found that CYP3A4 activities were correlated to the catalytic activities on most metabolic pathways of haloperidol. This suggests a prominent role for CYP3A4 in the metabolism of haloperidol. Among the recombinant CYP enzymes investigated, CYP1A1, CYP1A2, CYP3A4 were able to oxidize $\mathrm{RHP}^{+}$to $\mathrm{HP}^{+}$. Interestingly, $\mathrm{RHP}^{+}$ was shown to be a good substrate of CYP1A1 with activities about 50 times higher than CYP1A2 and
220 times higher than CYP3A4 $(17,18)$ under the experimental conditions.

While CYP1A1 is not normally present at detectable levels in human liver (19), it is expressed in extrahepatic tissues such as placenta (20), lung and intestine (21). Herein, we report that CYP1A1 plays an important role in the oxidation of $\mathrm{RHP}^{+}$to $\mathrm{HP}^{+}$in human placenta from smokers. Other enzymes such as CYP3A7 and CYP3A4 may play more important roles in placenta from non-smokers.

\section{MATERIALS AND METHODS}

\section{Materials}

$\mathrm{HP}^{+}$was synthesised as previously described (4). $\mathrm{RHP}^{+}$was a gift from Dr. Neal Castagnoli, Jr. (Virginia Tech, VA, USA). Pooled human liver microsomal preparations (HLM161), and human recombinant CYP1A1, CYP3A7 and CYP1A1 antiserum were purchased from Gentest Corporation (Woburn, MA, USA). Human placentas were obtained from Royal University Hospital (Saskatoon, SK, Canada) and microsomal preparations were prepared according to standard procedure as described previously (4). Protein levels in placenta microsomal preparations were determined using a commercial assay kit (Phenol reagent method for biologic fluids, Sigma diagnostics, St. Louis, MO, USA). The microsomal preparations were adjusted to protein concentration of $0.1 \mathrm{mg} / \mathrm{ml}$ for the enzymatic studies.

\section{HPLC analysis}

$\mathrm{HP}^{+}$and $\mathrm{RHP}^{+}$were analysed using a slight modification of an HPLC method described previously (22). Briefly, the system comprised a Waters 515 pump and a Waters $717_{\text {plus }}$ autosampler. A Waters 474 scanning fluorescence detector (excitation wavelength: $300 \mathrm{~nm}$; emission: $380 \mathrm{~nm}$ ) was used for the detection of $\mathrm{HP}^{+}$and $\mathrm{RHP}^{+}$. Signals from the fluorescence detector were collected and processed by a Waters Millennium 32 Chromatography Manager system. A Hypersil CN, $5 \mu \mathrm{m}$ column $(4.6 \times 250 \mathrm{~mm})$ (Phenomenex ${ }^{\mathbb{R}}$, Torrance, CA, USA) coupled with a SecurityGuard $^{\mathrm{TM}}$ guard cartridge system (Phenomenex $^{\circledR}$, Torrance, CA, USA) was utilised. The mobile phase consisted of acetonitrileammonium acetate buffer $(0.1 \mathrm{M})$-water $(67: 10: 23$ $\mathrm{v} / \mathrm{v})$. The mixture was adjusted to $\mathrm{pH} 5.4$ with acetic acid and the solvent was delivered at a flow rate of $1 \mathrm{ml} / \mathrm{min}$. 


\section{Enzymatic Studies}

Incubation procedures were as follows: $0.1 \mathrm{ml}$ reaction mixtures containing $10 \mu \mathrm{l}$ microsomal preparation (recombinant CYP3A7 or human liver microsomes or placenta microsomes from smokers or non-smokers), a cofactor-generating system [consisting of] $\beta$-nicotinamide adenine dinucleotide phosphate $(1.3 \mathrm{mM})$, glucose 6-phosphate $(3.3 \mathrm{mM})$, glucose 6-phosphate dehydrogenase $(0.4 \mathrm{U} / \mathrm{ml})$ and $\mathrm{MgCl}_{2}(3.3 \mathrm{mM})$ and appropriate concentrations of substrates (in phosphate buffer, $0.1 \mathrm{M}, \mathrm{pH}$ 7.4) the reaction mixtures enzyme preparations were incubated at $37{ }^{\circ} \mathrm{C}$. Control incubates contained heat-inactivated microsomes or control microsomes transfected with a control vector. Biological reactions were terminated by the addition of acetonitrile $(50 \mu \mathrm{l})$ and denatured proteins were removed by centrifugation. The clear supernatants were subjected to HPLC analysis.

For the panel study, placenta microsomes $(10 \mu \mathrm{l})$ from smokers or non-smokers were incubated with $20 \mu \mathrm{M} \mathrm{RHP}{ }^{+}$for $60 \mathrm{~min}$ in the presence of a cofactor-generating system. Biological reactions were terminated by the addition of acetonitrile (50 $\mu \mathrm{l})$ and denatured proteins were removed by centrifugation. The clear supernatants were subjected to HPLC analysis. A preliminary study confirmed that the enzymatic activity continue to increase significantly (but not linearly) with time at $60 \mathrm{~min}$. This incubation time was used so that enzymatic activities from all placenta samples can be quantified.

\section{Inhibition by CYP1A1 anti-serum}

For inhibition by antibody against CYP1A1, microsomal preparations (recombinant CYP1A1 or pooled placenta microsomes from smokers or nonsmokers, $10 \mu \mathrm{l})$ were mixed with CYP1A1 antiserum or normal goat serum and preincubated at room temperature for $30 \mathrm{~min}$. The microsome/antibody mixtures were then placed on ice and the following components added: a cofactor-generating system $[\beta$-nicotinamide adenine dinucleotide phosphate $(1.3 \mathrm{mM})$, glucose 6phosphate $(3.3 \mathrm{mM})$, glucose 6-phosphate dehydrogenase $(0.4 \mathrm{U} / \mathrm{ml})$ and $\mathrm{MgCl}_{2}(3.3 \mathrm{mM})$ ] and appropriate concentrations of substrates (in phosphate buffer, $0.1 \mathrm{M}, \mathrm{pH}$ 7.4). The total volume of reaction mixtures was $0.1 \mathrm{ml}$. The enzymatic reactions were started by transferring the mixture to a $37{ }^{\circ} \mathrm{C}$ water bath and were carried out for $10 \mathrm{~min}$. Biological reactions were terminated by the addition of acetonitrile $(50 \mu \mathrm{l})$ and denatured proteins were removed by centrifugation. The clear supernatants were subjected to HPLC analysis.

\section{Inhibition by chemical inhibitors}

For inhibition studies, incubation procedures were as follows: $0.1 \mathrm{ml}$ reaction mixtures containing a cofactor-generating system [consisting of] $\beta$ nicotinamide adenine dinucleotide phosphate (1.3 $\mathrm{mM})$, glucose 6-phosphate $(3.3 \mathrm{mM})$, glucose 6 phosphate dehydrogenase $(0.4 \mathrm{U} / \mathrm{ml})$ and $\mathrm{MgCl}_{2}$ $(3.3 \mathrm{mM})$ and appropriate concentrations of substrates and inhibitors [in phosphate buffer, 0.1 $\mathrm{M}, \mathrm{pH}$ 7.4]. To the above reactions mixtures were added $10 \mu \mathrm{l}$ microsomal preparation (human liver microsomes, placenta microsomes from smokers or non-smokers) and enzymatic reactions were carried out at $37{ }^{\circ} \mathrm{C}$ for $60 \mathrm{~min}$. Biological reactions were terminated by the addition of acetonitrile $(50 \mu \mathrm{l})$ and denatured proteins were removed by centrifugation. The clear supernatant was subjected to HPLC analysis. The selective inhibitors used are furafylline (CYP1A1/CYP1A2), ketoconozole (CYP3A4), and $\alpha$-naphthoflavone (CYP1A2). Their concentrations in the incubation mixtures are as shown in Figure 3.

\section{RESULTS}

The present study demonstrated catalytic activities present in human placenta microsomes. These activities for the oxidation of RHP were not present in control incubates without microsomes, without the NADPH generating system, without the substrates, or with heat-inactivated microsomal preparation (by incubating in boiling water for 10 min). This confirmed that the observed oxidation of $\mathrm{RHP}^{+}$is catalysed by enzymes requiring NADPH.

A series of studies was conducted to characterize the enzyme(s) responsible for the oxidation of $\mathrm{RHP}^{+}$in human placenta microsomes and the effect of smoking. Firstly, recombinant human CYP3A7 was shown to catalyse the oxidation of $\mathrm{RHP}^{+}$at a rate of $4.90 \pm 0.26 \mathrm{pmol} / \mathrm{pmol}$ $\mathrm{P} 450 / \mathrm{h}$. This adds to the list of enzymes capable of catalysing this reaction (CYP1A1, CYP1A2, CYP3A4) $(17,18)$. Secondly, the oxidation of $\mathrm{RHP}^{+}$to $\mathrm{HP}^{+}$was investigated using human placenta microsomal preparations from 12 smokers and 12 non-smokers (Figure 1). A comparison of the metabolic activities between smokers and nonsmokers suggests that smokers had slight, but statistically significant higher activities for the oxidation of $\mathrm{RHP}^{+}$. Thirdly, an inhibitory antibody against human CYP1A1 was investigated for its ability to inhibit the oxidation of $\mathrm{RHP}^{+}$(Figure 2). The antiserum was shown to be a partial inhibitor of $\mathrm{RHP}^{+}$oxidase in placenta preparations from smokers but had no effect in placenta preparations 
from non-smokers. Finally, different chemical inhibitors were investigated for their capacity to inhibit the oxidation of $\mathrm{RHP}^{+}$(Figure 3). Ketoconazole and furafylline were shown to be stronger inhibitors of the oxidation of $\mathrm{RHP}^{+}$to $\mathrm{HP}^{+}$ in human liver microsomes than in human placenta microsomes. $\alpha$-Naphathoflavone enhanced the metabolic activity in human liver microsomes but partially inhibited the activity in placenta microsomes.

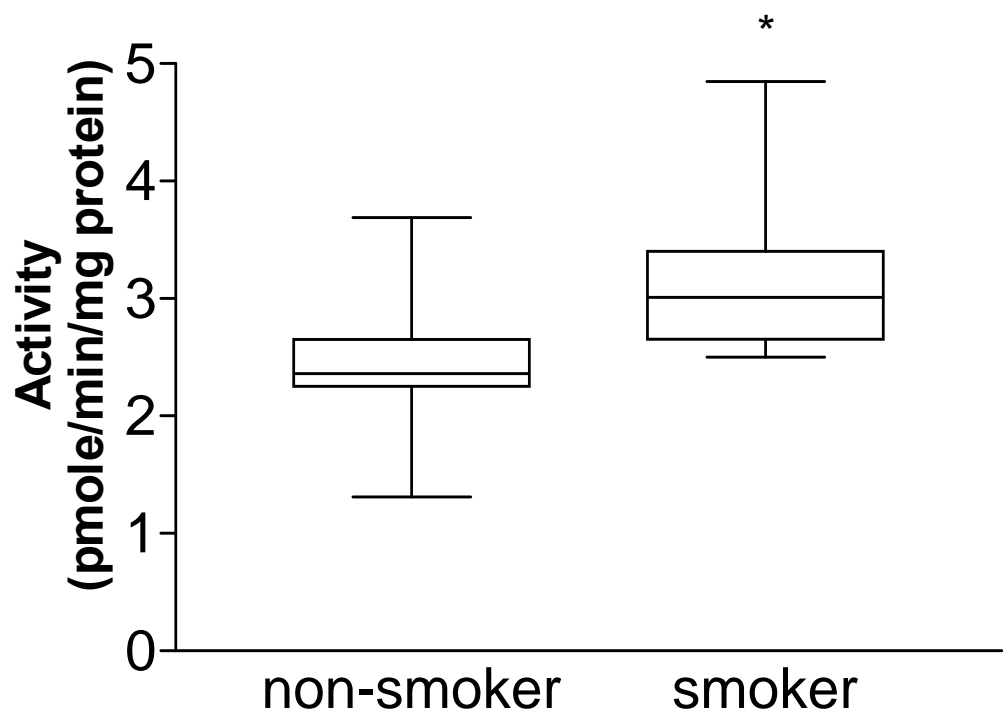

Figure 1. Comparison of the rate of oxidation of $\mathrm{RHP}^{+}$to $\mathrm{HP}^{+}$in placental microsomal preparations from smokers $(\mathrm{n}=12)$ and non-smokers $(\mathrm{n}=12)$. Box-and-whiskers graph. The box extends from the 25th to the 75th percentile and the line at the middle is the median. The error bars, or whiskers extend down to the lowest value and up to the highest. * $\mathrm{P}<0.05$ (MannWhitney U test)

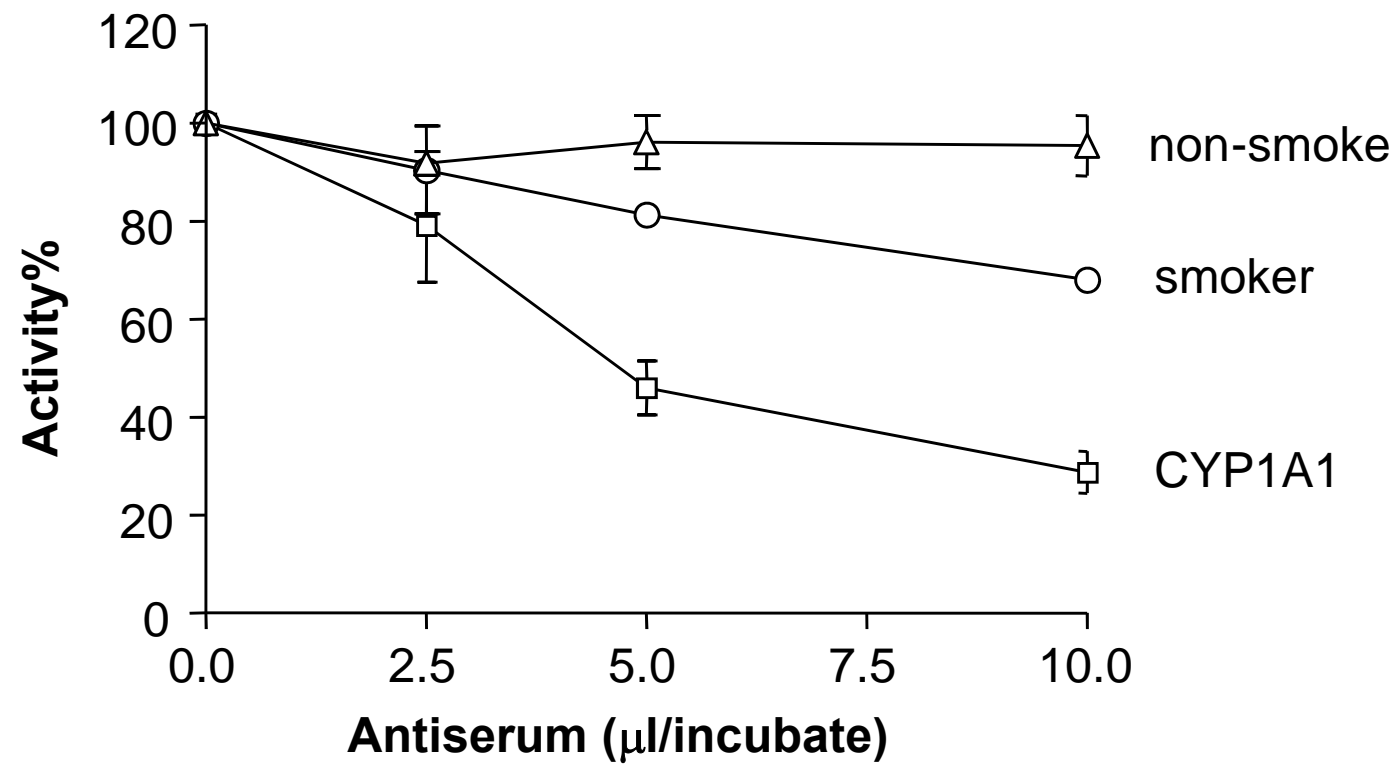

Figure 2. Effects of an antiserum against CYP1A1 on the metabolism of $\mathrm{RHP}^{+}$by recombinant $\mathrm{CYP} 1 \mathrm{~A} 1$ and human placenta from smokers and non-smokers. 

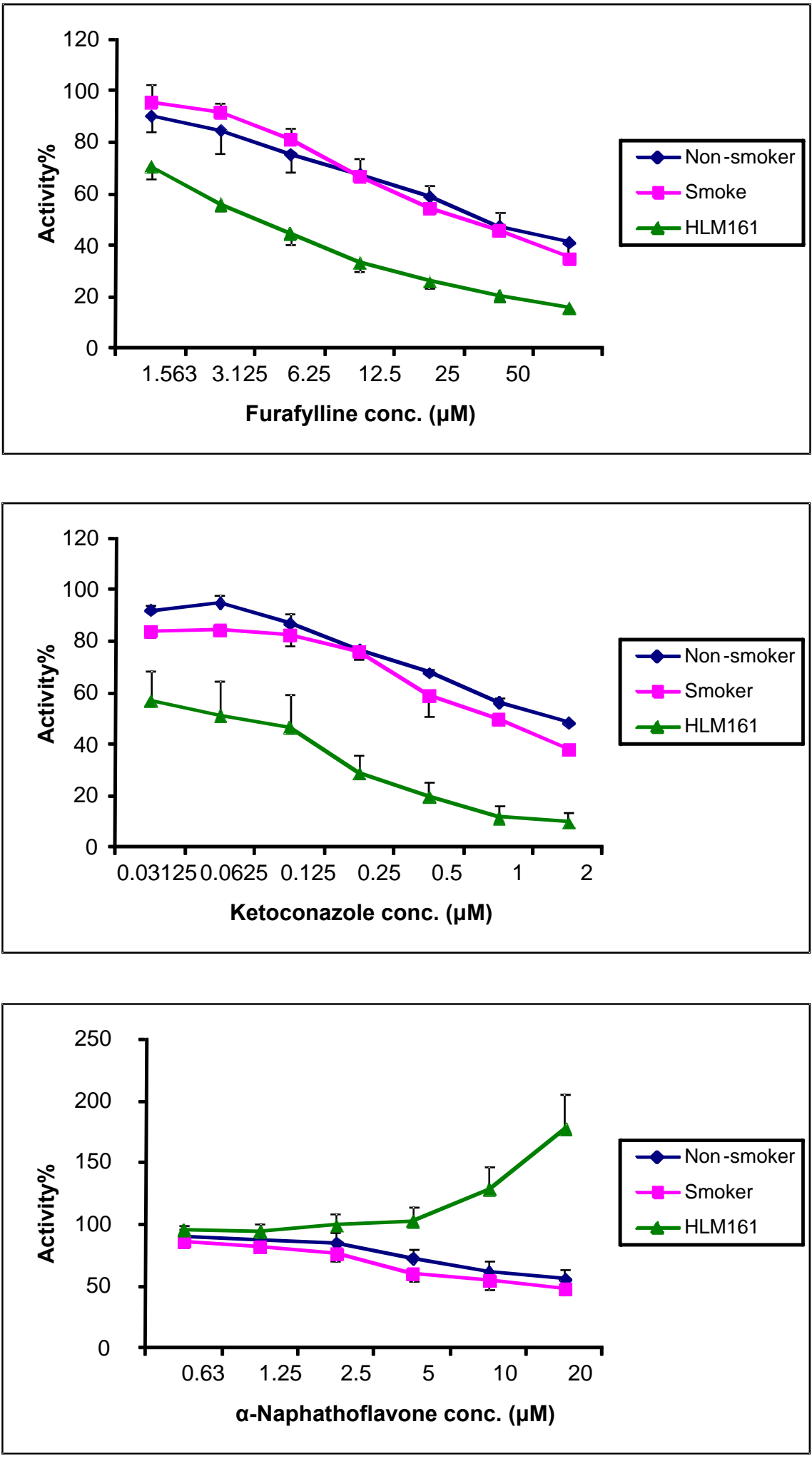

Figure 3. Effects of furafylline, ketoconazole and $\alpha$-naphathoflavone on the oxidation of $\mathrm{RHP}^{+}$in human liver and placenta from smokers and nonsmokers. 


\section{DISCUSSION}

\section{CYP enzymes responsible for the oxidation of RHP $^{+}$}

$\mathrm{RHP}^{+}$was investigated as a substrate of recombinant CYP1A1, CYP1A2, CYP2C8, CYP2C9, CYP2C19, CYP2D6, CYP2E1, CYP3A4 and CYP3A5 (17). Recombinant CYP1A1 showed the highest activity (123.9 pmol/pmol P450/h) followed by CYP3A7 (4.90 pmol/pmol P450/h), CYP1A2 (2.55 pmol/pmol P450/h), and CYP3A4 (0.56 pmol/pmol P450/h). Recombinant CYP2C8, CYP2C9, CYP2C19, CYP2D6 and CYP3A5 did not show detectable activity for this metabolic reaction.

In human liver microsomes, CYP3A4 seems to be the dominant enzyme responsible for the oxidation of $\mathrm{RHP}^{+}$to $\mathrm{HP}^{+}$. This conclusion is supported by the study with recombinant CYP isoenzymes, a correlation study and the fact that the enzyme activity can be inhibited by ketoconazole, a selective inhibitor of CYP3A4 (17). Although recombinant CYP1A2 is shown to be able to catalyse the oxidation of $\mathrm{RHP}^{+}$to $\mathrm{HP}^{+}$, there is not a significant correlation between this catalytic activity and catalytic and immunoactivities of CYP1A2 (17). Thus, it seems that CYP1A2 plays only a minor role in the oxidation of $\mathrm{RHP}^{+}$to $\mathrm{HP}^{+}$ in human liver.

\section{Effects of smoking}

CYP1A1 is said to be the most important xenobiotic-metabolizing enzyme of the placenta (23). Placenta mRNAs of CYP1A1, CYP1A2, CYP2C, CYP2D6, CYP2E1, CYP2F1, CYP3A4, CYP3A5, CYP3A7 and CYP4B1 have been detected in the first trimester while CYP1A1, CYP2E1, CYP2F1, CYP3A3, CYP3A4, CYP3A5 and CYP4B1 mRNAs are expressed in the full-term placenta (24-26). However, not all of these mRNAs translated into detectable proteins or catalytic activity. CYP1A1 is the only placental CYP enzyme for which significant expression has been conclusively demonstrated in the placenta throughout the entire pregnancy.

In order to further characterize $\mathrm{RHP}^{+}$as a substrate of CYP1A1, more study were carried out using human placenta microsomal preparations from smokers and non-smokers. Placenta microsomal preparations from smokers exhibited higher catalytic activities for the oxidation of $\mathrm{RHP}^{+}$ than those from non-smokers (Figure 1). This elevated enzyme activity is likely due to the induction of CYP1A1 by smoking because the placentas were from women of similar ages. It is well-established that smoking can induce placental CYP1A1 at the mRNA level (27-31) and at protein and enzyme activity level (32-37).

\section{Effects of antibodies against CYP1A1}

Selective antibodies against CYP1A1 were used to further characterize the contribution of CYP1A1 to the oxidation of $\mathrm{RHP}^{+}$. It was shown that the antiserum could inhibit the oxidation of $\mathrm{RHP}^{+}$in microsomal preparations from smokers and placenta recombinant CYP1A1. The antiserum did not exhibit an inhibitory effect in microsomes from non-smokers (Figure 2). Smoking placenta seems to increase the relative contribution of CYP1A1, making the placenta more sensitive to the inhibition by the antiserum of CYP1A1. Thus, although CYP1A1 plays an important role in the oxidation of $\mathrm{RHP}^{+}$in placenta from smokers, CYP enzyme(s) other than CYP1A1 probably play(s) an important role for the conversion of $\mathrm{RHP}^{+}$to $\mathrm{HP}^{+}$in placenta from non-smokers. mRNAs of CYP1A1, CYP3A3/4, and CYP3A5 were detected in full-term human placenta by reverse transcriptase-polymerase chain reaction (RT-PCR) (20, 38). Immunoblot analysis of microsomes from placentas from early pregnancy revealed immunoreactive bands by an antihuman CYP3A4 antibody (38). Therefore, in addition to CYP1A1, the other contributing enzyme responsible for the oxidation of $\mathrm{RHP}^{+}$could be CYP3A4 or CYP3A7.

\section{Effects of selective inhibitors of CYP}

Thus, another series of experiments were carried out to investigate the inhibition of the oxidation of $\mathrm{RHP}^{+}$to $\mathrm{HP}^{+}$by furafylline, ketoconozole, and $\alpha-$ naphthoflavone (Figure 3). Furafylline can inhibit the oxidation of $\mathrm{RHP}^{+}$to $\mathrm{HP}^{+}$in human liver microsomal preparations. In human placenta microsomal preparations, furafylline was shown to partially inhibit the oxidation of $\mathrm{RHP}^{+}$to $\mathrm{HP}^{+}$, indicating a role for CYP1A2 and/or CYP1A1 in catalysing this reaction. Furafylline inhibits the oxidation of $\mathrm{RHP}^{+}$to a similar degree in placenta microsomal preparations from both smokers and non-smokers. This may be explained by the fact that smoking selectively induces CYP1A1 and that furafylline is a weaker inhibitor of CYP1A1 as compared to CYP1A2 (39). Furafylline was shown to selectively inhibit CYP1A2 at concentrations 
below $20 \mu \mathrm{M}$, but can inhibit CYP1A1 at higher concentrations. It was shown that furafylline did not inhibit CYP1A1 in placenta from smokers (40). Inhibition of multiple enzymes with different $\mathrm{IC}_{50} \mathrm{~S}$ leads to a flatter inhibition curve (41). This phenomenon was observed in the inhibition curves of furafylline, ketoconozole, and $\alpha$-naphthoflavone (Figure 3).

Ketoconazole, a CYP3A4 inhibitor, showed a relatively weak inhibitory effect to the oxidation of $\mathrm{RHP}^{+}$in placenta as compared to that in liver (Figure 3). This indicates a less important role of CYP3A4 in the oxidation of $\mathrm{RHP}^{+}$in human placenta. The CYP3A enzymes are different in their susceptibility to inhibition by inhibitors. For example, ketoconazole was shown to inhibit CYP3A4 more strongly than CYP3A5 and CYP3A7 $(42,43)$. It is therefore suggested that CYP3A7 could contribute to the oxidation of RHP ${ }^{+}$ in placenta. On the other hand, ketoconozole can strongly inhibit the oxidation of $\mathrm{RHP}^{+}$to $\mathrm{HP}^{+}$in human liver microsomal preparations. This is consistent with the notion that CYP3A4 is primarily responsible for the oxidation of $\mathrm{RHP}^{+}$to $\mathrm{HP}^{+}$in human liver.

$\alpha$-Naphathoflavone was shown to be able to partially inhibit the oxidation of $\mathrm{RHP}^{+}$in placenta microsomes (Figure 3). $\alpha$-Naphthoflavone was also found to be approximately 10 -fold more potent as an inhibitor of CYP1A2 than CYP1A1 (44). Interestingly, $\alpha$-naphthoflavone can significantly enhance the oxidation of $\mathrm{RHP}^{+}$in human liver microsomes, but not in placenta microsomal preparations. This suggests that CYP3A4 does not play an important role in the oxidation of $\mathrm{RHP}^{+}$in human placenta microsomes. Activation of CYP3A4 by $\alpha$-naphthoflavone has been observed previously (45), and was attributed to the allosteric effect of $\alpha$-naphthoflavone (46). Thus, the activation property of $\alpha$-naphthoflavone on CYP3A4 seems to dominate in human liver microsomes.

\section{Clinical implications}

Antipsychotic medications, including haloperidol, are prescribed for pregnant women (47). Most women with a serious psychiatric illness cannot stop taking their medication because this would interfere with their daily activities and care of an infant. Although most toxicological studies were carried out using $\mathrm{HP}^{+}$only, there are evidences to indicate that $\mathrm{RHP}^{+}$and $\mathrm{HP}^{+}$have different biological properties. For example, $\mathrm{RHP}^{+}$was found to be less potent than $\mathrm{HP}^{+}$in inhibition of serotonin and dopamine uptake and in releasing preloaded dopamine from striatal synaptosomes (48). $\mathrm{RHP}^{+}$and $\mathrm{HP}^{+}$also exhibited different selectivity as substrates of human organic cation transporters (8). A clinical study demonstrated that the severity of tardive dyskinesia and parkinsonism is associated with an increased ratio of $\mathrm{HP}^{+}$/haloperidol in serum (15). This may be interpreted as evidence that $\mathrm{RHP}^{+}$is less toxic than $\mathrm{HP}^{+}$.

It is known that pregnancy outcomes could be affected by maternal smoking. For example, lower birth weight and shorter gestational age have been associated with smoking mothers with the CYP1A1 Mspl variant genotype (Aa/aa), which seem to have higher enzyme activity $(49,50)$. Nevertheless, one should still be cautious to suggest that the modest increase in the oxidation of $\mathrm{RHP}^{+}$observed among smokers would have significant clinical consequences.

Taken together, these data seem to indicate that CYP1A1 plays an important role in the oxidation of $\mathrm{RHP}^{+}$in placenta from smokers. Other enzymes such as CYP3A7 and CYP3A4 may play more important roles than CYP1A1 in placenta from nonsmokers.

\section{ACKNOWLEDGEMENTS}

Funds were provided by the Canadian Institutes for Health Research (Grant No: MT-14724). RHP ${ }^{+}$was a gift from Dr. Neal Castagnoli, Jr. (Virginia Tech, VA, USA).

\section{REFERENCES}

1. Subramanyam B, Pond SM, Eyles DW, Whiteford HA, Fouda HG, and Castagnoli N, Jr. Identification of potentially neurotoxic pyridinium metabolite in the urine of schizophrenic patients treated with haloperidol. Biochem Biophys Res Commun, 1991; 181:573-578.

2. Fang J and Gorrod JW. Dehydration is the first step in the bioactivation of haloperidol to its pyridinium metabolite. Toxicol Lett, 1991; 59:117-123.

3. Subramanyam B, Rollema $\mathrm{H}$, Woolf $\mathrm{T}$, and Castagnoli N. Identification of a potentially neurotoxic pyridinium metabolite of haloperidol in rats. Biochem Biophys Res Commun, 1990; 166:238-244.

4. Gorrod JW and Fang J. On the Metabolism of 
Haloperidol. Xenobiotica, 1993; 23:495-508.

5. Eyles DW, McLennan HR, Jones A, McGrath JJ, Stedman TJ, and Pond SM. Quantitative analysis of two pyridinium metabolites of haloperidol in patients with schizophrenia. Clin Pharmacol Ther, 1994; 56:512-520.

6. Eyles DW, Avent KM, Stedman TJ, and Pond SM. Two pyridinium metabolites of haloperidol are present in the brain of patients at post-mortem. Life Sci, 1997; 60:529-534.

7. Kawashima H, Iida $\mathrm{Y}$, Kitamura $\mathrm{Y}$, Kiyono $\mathrm{Y}$, Magata Y, and Saji H. Brain extraction of 4-(4chlorophenyl)-1-[4-(4-fluorophenyl)-4-

oxobutyl]pyridinium ion ( $\mathrm{HPP}+)$, a neurotoxic metabolite of haloperidol: studies using $[3 \mathrm{H}] \mathrm{HPP}+$. Jpn J Pharmacol, 2002; 89:426-428.

8. Kang H-J, Lee S-S, Lee C-H, Shim J-C, Shin HJ, Liu K-H, Yoo M-A, and Shin J-G. Neurotoxic pyridinium metabolites of haloperidol are substrates of human organic cation transporters. Drug Metab Dispos, 2006; 34:1145-1151.

9. Halliday GM, Pond SM, Cartwright H, McRitchie DA, Castagnoli N, Jr., and Van der Schyf CJ. Clinical and neuropathological abnormalities in baboons treated with HPTP, the tetrahydropyridine analog of haloperidol. Exp Neurol, 1999; 158:155163.

10. Rollema H, Skolnik M, D'Engelbronner J, Igarashi $\mathrm{K}$, Usuki E, and Castagnoli N, Jr. MPP(+)-like neurotoxicity of a pyridinium metabolite derived from haloperidol: in vivo microdialysis and in vitro mitochondrial studies. The Journal of pharmacology and experimental therapeutics, 1994; 268:380-387.

11. Bloomquist J, King E, Wright A, Mytilineou C, Kimura K, Castagnoli K, and Castagnoli N. 1Methyl-4-Phenylpyridinium-Like Neurotoxicity of a Pyridinium Metabolite Derived from Haloperidol Cell-Culture and Neurotransmitter Uptake Studies. Journal of Pharmacology and Experimental Therapeutics, 1994; 270:822-830.

12. Fang J, Zuo D, and $\mathrm{Yu} \mathrm{PH}$. Comparison of Cytotoxicity of a Quaternary Pyridinium Metabolite of Haloperidol $\left(\mathrm{Hp}^{+}\right)$with Neurotoxin N-Methyl-4Phenylpyridinium $(\mathrm{Mpp}(+))$ Towards Cultured Dopaminergic Neuroblastoma-Cells. Psychopharmacology (Berl), 1995; 121:373-378.

13. Fang $\mathrm{J}$ and $\mathrm{Yu} \mathrm{PH}$. Effect of Haloperidol and Its Metabolites on Dopamine and Noradrenaline Uptake in Rat Brain-Slices. Psychopharmacology (Berl), 1995; 121:379-384.

14. Fang J, Yu PH, Gorrod JW, and Boulton AA. Inhibition of Monoamine Oxidases by Haloperidol and Its Metabolites - Pharmacological Implications for the Chemotherapy of Schizophrenia. Psychopharmacology (Berl), 1995; 118:206-212.

15. Ulrich S, Sandmann U, and Genz A. Serum concentrations of haloperidol pyridinium metabolites and the relationship with tardive dyskinesia and parkinsonism: a cross-section study in psychiatric patients. Pharmacopsychiatry, 2005; 38:171-177.

16. Stubner S, Rustenbeck E, Grohmann R, Wagner G, Engel R, Neundorfer G, Moller HJ, Hippius H, and Ruther E. Severe and uncommon involuntary movement disorders due to psychotropic drugs. Pharmacopsychiatry, 2004; 37 Suppl 1:S54-64.

17. Fang J, McKay G, Song J, Remillrd A, Li X, and Midha K. In vitro characterization of the metabolism of haloperidol using recombinant cytochrome p450 enzymes and human liver microsomes. Drug Metab Dispos, 2001; 29:1638-1643.

18. Fang J, Baker GB, Silverstone PH, and Coutts RT. Involvement of CYP3A4 and CYP2D6 in the metabolism of haloperidol. Cellular and molecular neurobiology, 1997; 17:227-233.

19. McKinnon RA, Hall PD, Quattrochi LC, Tukey RH, and McManus ME. Localization of CYP1A1 and CYP1A2 messenger RNA in normal human liver and in hepatocellular carcinoma by in situ hybridization. Hepatology, 1991; 14:848-856.

20. Hakkola J, Pasanen M, Hukkanen J, Pelkonen O, Maenpaa J, Edwards RJ, Boobis AR, and Raunio H. Expression of xenobiotic-metabolizing cytochrome P450 forms in human full-term placenta. Biochem Pharmacol, 1996; 51:403-411.

21. Ding $X$ and Kaminsky LS. Human extrahepatic cytochromes P450: function in xenobiotic metabolism and tissue-selective chemical toxicity in the respiratory and gastrointestinal tracts. Annu Rev Pharmacol Toxicol, 2003; 43:149-173.

22. Fang $\mathrm{J}$ and Gorrod JW. High-performance liquid chromatographic method for the detection and quantitation of haloperidol and seven of its metabolites in microsomal preparations. $J$ Chromatogr, 1993; 614:267-273.

23. Stejskalova L and Pavek P. The function of cytochrome P450 1A1 enzyme (CYP1A1) and aryl hydrocarbon receptor (AhR) in the placenta. Curr Pharm Biotechnol, 2011; 12:715-730.

24. Myllynen P, Pasanen M, and Vahakangas K. The fate and effects of xenobiotics in human placenta. Expert Opin Drug Metab Toxicol, 2007; 3:331-346.

25. Syme MR, Paxton JW, and Keelan JA. Drug transfer and metabolism by the human placenta. Clin Pharmacokinet, 2004; 43:487-514.

26. Pavek P, Ceckova M, and Staud F. Variation of drug kinetics in pregnancy. Curr Drug Metab, 2009; 10:520-529.

27. Pasanen M, Haaparanta T, Sundin M, Sivonen P, Vakakangas K, Raunio H, Hines R, Gustafsson JA, and Pelkonen O. Immunochemical and Molecular Biological Studies on Human Placental Cigarette Smoke-Inducible Cytochrome-P-450-Dependent Monooxygenase Activities. Toxicology, 1990; 
62:175-187.

28. Huuskonen P, Storvik M, Reinisalo M, Honkakoski P, Rysa J, Hakkola J, and Pasanen M. Microarray analysis of the global alterations in the gene expression in the placentas from cigarette-smoking mothers. Clinical Pharmacology \& Therapeutics, 2008; 83:542-550.

29. Bruchova H, Vasikova A, Merkerova M, Milcova A, Topinka J, Balascak I, Pastorkova A, Sram RJ, and Brdicka R. Effect of Maternal Tobacco Smoke Exposure on the Placental Transcriptome. Placenta, 2010; 31:186-191.

30. Hakkola J, Pasanen M, Hukkanen J, Pelkonen O, Maenpaa J, Edwards RJ, Boobis AR, and Raunio H. Expression of xenobiotic-metabolizing cytochrome P450 forms in human full-term placenta. Biochem Pharmacol, 1996; 51:403-411.

31. Whyatt RM, Bell DA, Jedrychowski W, Santella RM, Garte SJ, Cosma G, Manchester DK, Young TL, Cooper TB, Ottman R, and Perera FP. Polycyclic aromatic hydrocarbon-DNA adducts in human placenta and modulation by CYP1A1 induction and genotype. Carcinogenesis, 1998; 19:1389-1392.

32. Czekaj P, Wiaderkiewicz A, Florek E, and Wiaderkiewicz R. Tobacco smoke-dependent changes in cytochrome P450 1A1, 1A2, and 2E1 protein expressions in fetuses, newborns, pregnant rats, and human placenta. Arch Toxicol, 2005; 79:13-24.

33. Hakkola J, Pasanen M, Pelkonen O, Hukkanen J, Evisalmi S, Anttila S, Rane A, Mantyla M, Purkunen R, Saarikoski S, Tooming M, and Raunio $\mathrm{H}$. Expression of CYP1B1 in human adult and fetal tissues and differential inducibility of CYP1B1 and CYP1A1 by Ah receptor ligands in human placenta and cultured cells. Carcinogenesis, 1997; 18:391397.

34. Collier AC, Tingle MD, Paxton JW, Mitchell MD, and Keelan JA. Metabolizing enzyme localization and activities in the first trimester human placenta: the effect of maternal and gestational age, smoking and alcohol consumption. Human Reproduction, 2002; 17:2564-2572.

35. Boden AG, Bush PG, Burke MD, Abramovich DR, Aggett P, Mayhew TM, and Page KR. Human placental cytochrome $\mathrm{P} 450$ and quinone reductase enzyme induction in relation to maternal smoking. Reprod Fert Develop, 1995; 7:1521-1524.

36. Kaelin AC and Cummings AJ. A Survey of ArylHydrocarbon Hydroxylase-Activity in Human Placental Homogenates. Placenta, 1983; 4:471-478.

37. Okey AB, Giannone JV, Smart W, Wong JMY, Manchester DK, Parker NB, Feeley MM, Grant DL, and Gilman A. Binding of 2,3,7-8tetrachlorodibenzo-p-dioxin to $\mathrm{AH}$ receptor in placentas from normal versus abnormal pregnancy outcomes. Chemosphere, 1997; 34:1535-1547.

38. Hakkola J, Raunio H, Purkunen R, Pelkonen O, Saarikoski S, Cresteil T, and Pasanen M. Detection of cytochrome P450 gene expression in human placenta in first trimester of pregnancy. Biochem Pharmacol, 1996; 52:379-383.

39. Tassaneeyakul W, Birkett DJ, Veronese ME, McManus ME, Tukey RH, and Miners JO. Direct characterization of the selectivity of furafylline as an inhibitor of human cytochromes P450 1A1 and 1A2. Pharmacogenetics, 1994; 4:281-284.

40. Sesardic D, Boobis AR, Murray BP, Murray S, Segura J, de la Torre R, and Davies DS. Furafylline is a potent and selective inhibitor of cytochrome P450IA2 in man. Br J Clin Pharmacol, 1990; 29:651-663.

41. Viola MS and Rodriguez de Lores Arnaiz G. Brain $\mathrm{Na}+, \mathrm{K}+$-ATPase isoforms: different hypothalamus and mesencephalon response to acute desipramine treatment. Life Sci, 2007; 81:228-233.

42. Gibbs MA, Thummel KE, Shen DD, and Kunze KL. Inhibition of cytochrome P-450 3A (CYP3A) in human intestinal and liver microsomes: comparison of $\mathrm{Ki}$ values and impact of CYP3A5 expression. Drug Metab Dispos, 1999; 27:180-187.

43. Stresser DM, Broudy MI, Ho T, Cargill CE, Blanchard AP, Sharma R, Dandeneau AA, Goodwin JJ, Turner SD, Erve JCL, Patten CJ, Dehal SS, and Crespi CL. Highly selective inhibition of human CYP3Aa in vitro by azamulin and evidence that inhibition is irreversible. Drug Metab Dispos, 2004; 32:105-112.

44. Tassaneeyakul W, Birkett DJ, Veronese ME, McManus ME, Tukey RH, Quattrochi LC, Gelboin HV, and Miners JO. Specificity of substrate and inhibitor probes for human cytochromes P450 1A1 and 1A2. The Journal of pharmacology and experimental therapeutics, 1993; 265:401-407.

45. Schwab GE, Raucy JL, and Johnson EF. Modulation of Rabbit and Human Hepatic Cytochrome-P-450Catalyzed Steroid Hydroxylations by AlphaNaphthoflavone. Mol Pharmacol, 1988; 33:493-499.

46. Woods CM, Fernandez C, Kunze KL, and Atkins WM. Allosteric Activation of Cytochrome P450 3A4 by alpha-Naphthoflavone: Branch Point Regulation Revealed by Isotope Dilution Analysis. Biochemistry, 2011; 50:10041-10051.

47. Einarson A and Boskovic R. Use and safety of antipsychotic drugs during pregnancy. J Psychiatr Pract, 2009; 15:183-192.

48. Wright AM, Bempong J, Kirby ML, Barlow RL, and Bloomquist JR. Effects of haloperidol metabolites on neurotransmitter uptake and release: possible role in neurotoxicity and tardive dyskinesia. Brain Res, 1998; 788:215-222.

49. Wang X, Zuckerman B, Pearson C, Kaufman G, Chen C, Wang G, Niu T, Wise PH, Bauchner H, and 
$\mathrm{Xu} \mathrm{X}$. Maternal cigarette smoking, metabolic gene polymorphism, and infant birth weight. Jama, 2002; 287:195-202.

50. Sasaki S, Kondo T, Sata F, Saijo Y, Katoh S, Nakajima S, Ishizuka M, Fujita S, and Kishi R.
Maternal smoking during pregnancy and genetic polymorphisms in the Ah receptor, CYP1A1 and GSTM1 affect infant birth size in Japanese subjects. Mol Hum Reprod, 2006; 12:77-83. 